\title{
PRAKTIK NIKAH BATIN \\ DI KABUPATEN PADANG PARIAMAN
}

\author{
Yusri Amir, M.Ag dan Taufik Hidayat, MA, MH. \\ UIN Imam Bonjol Padang \\ Email: yusriamir86@yahoo.co.id
}

\begin{abstract}
Abstrak
Dalam sebuah tugas pengabdian kepada masyarakat yang berjudul "Pelatihan Hukum Bagi BP4 Kecamatan Lubuk Alung Kabupaten Padang Pariaman", peneliti (pada saat itu dosen pengabdian) menemukan permasalahan yang dikemukakan oleh beberapa orang peserta pelatihan yaitu permasalahan nikah batin.Tentunya konsep nikah batin ini di luar dari konsep nikah yang telah digariskan oleh fiqih. Nikah batin adalah nikah yang dilakukan oleh seorang pria dengan seorang wanita pada malam pertama sebelum melakukan hubungan suami istri, setelah mereka melaksanakan nikah secara syariat Islam. Nikah batin ini mencontoh kepada nikahnya Nabi Adam dan Siti Hawa di mana Allah SWT sebagai walinya dan malaikat sebagai saksinya dengan mahar dua kalimat syahadat yang bertujuan untuk mendekatkan diri kepada Allah SWT. Amalan nikah batin merupakan ajaran yang terdapat dalam tarekat Syatariyyah Padang Pariaman Sumatera Barat. Urgennya nikah batin tersebut dalam rangka mendekatkan diri kepada Allah dan mencapai kesempurnaan amalan seorang hamba, yakni secara syariat dan hakikat. Nikah batin dipahami masyarakat Kabupaten Padang Pariaman sebagai penyempurna pernikahan yang telah dilaksanakan secara syariat, agar diperoleh penyatuan batin antara suami dengan istri dalam rangka membentuk rumah tangga yang sakinah, mawaddah, wa rahmah. Bagi Lembaga Keagamaan (Kantor Urusan Agama), tidak ada pemisahan antara nikah lahir dan nikah batin, karena pernikahan yang diselenggarakan di KUA sudah terjalin hubungan suami istri secara lahir dan batin.
\end{abstract}

Kata Kunci: Nikah batin, pernikahan syariat, hubungan lahir dan batin

\section{PENDAHULUAN}

Dalam sebuah tugas pengabdian kepada masyarakat yang berjudul Pelatihan Hukum Bagi BP4 Kecamatan Lubuk Alung Kabupaten Padang Pariaman, peneliti menemukan fenomena nikah batin di tengah masyarakat setempat. Tentunya konsep nikah batin ini di luar dari konsep nikah yang telah digariskan oleh fiqih. Pada penelitian awal, didaptkan data bahwa batin dilakukan setelah mereka nikah secara sah. Hal tersebut diperkuat oleh pengakuan dari Wali Korong Sintuk Timur Kec.Sintuk Toboh Gadang Kab. Padang Pariaman (Raziom, SH) bahwa beliau juga melakukan nikah batin dengan istrinya setelah mereka menikah secara sah di Kantor Urusan Agama (KUA).

Berangkat dari latar fenomena di atas, maka penelitian ini mempertanyakan bagaimana bentuk praktek nikah batin di Kabupaten Padang Pariaman. Untuk membatasi pertanyaan tersebut peneliti membatasi pertanyaan pada empat pertanyaan penelitian: 1) Apa makna nikah batin pada masyarakat Kabupaten Padang Pariaman; 2) bagaimana proses pelaksanaan nikah batin di Kabupaten Padang Pariaman; 3) apa urgensi nikah batin bagi masyarakat Kabupaten Padang Pariaman; dan 4), bagaimana respon lembaga keagamaan Islam di Kabupaten Padang Pariaman terhadap 
praktik nikah batin.

Adapun tujuan penelitian ini adalah untuk mengetahui beberapa hal sebagai berikut: Pertama, makna nikah batin di kabupaten Padang Pariaman; Kedua, proses pelaksanaan nikah batin di Kabupaten Padang Pariaman; Ketiga, urgensi nikah batin bagi masyarakat kabupaten Padang Pariaman; Keempat, respon lembaga keagamaan Islam di Kabupaten Padang Pariaman terhadap praktik nikah batin.

\section{METODE PENELITIAN}

Sesuai dengan judul penelitian ini yaitu "Praktik Nikah Batin di Kabupaten Padang Pariaman", maka jenis penelitian ini adalah penelitian hukum yang sosiologis berbentuk identifikasi hukum tidak tertulis dengan metode penelitian deskriptif kualitatif. Penelitian hukum yang sosiologis terdiri dari dua bentuk: 1) penelitian berlakunya hukum, yang meliputi penelitian efektivitas hukum dan Penelitian dampak hukum. 2) Penelitian identifikasi hukum tidak tertulis.

Sumber data dalam penelitian ini diklasifikasikan menjadi dua sumber data, yaitu: 1) Sumber data primer adalah data yang diperoleh atau dikumpulkan langsung di lapangan. Sumber data primer di sini adalah hasil wawancara dengan pasangan suami isteri yang melakukan nikah batin dan tokoh masyarakat selaku orang yang menganjurkan nikah batin kepada masyarakat. 2) Sumber data sekunder adalah data yang diperoleh dan dikumpulkan dari sumber-sumber yang telah ada. Menurut Hasan (2002: 82) data sekunder disebut juga data yang tersedia, seperti undang-undang, bukubuku, artikel dari media masa dan bahan informasi lainnya yang berkaitan dengan masalah penelitian. Sumber data sekunder merupakan sumber data awal yang penulis gunakan yang kemudian dilanjutkan dengan data primer atau lapangan. Dengan demikian, penelitian hukum yang normatif tetap bertumpu pada premis normatif, berbeda dengan penelitian ilmu-ilmu sosial yang hendak mengkaji hukum, di mana hukum ditempatkan sebagai dependent variable (Amiruddin dan Zainal, 2010).

Dalam hal menguraikan setiap data tentang nikah batin yang terjadi di Kabupaten Padang Pariaman diperoleh melalui wawancara untuk menjelaskan makna, praktek dan urgensi nikah batin serta respon terhadap nikah batin. Selanjutnya data ini dideskripsikan dengan menggunakan teknik analisis yang dikemukakan oleh Miles dan Hubermen (1992) yaitu reduksi data, penyajian data verifikasi (menarik kesimpulan). Reduksi data di sini adalah proses pemilihan pemusatan perhatian pada penyederhanaan, pengabstrakan dan transformasi data kasar yang muncul dari catatan-catatan tertulis dalam mengolah hasil wawancara tentang praktek nikah batin. Penyajian data di sini adalah sekumpulan informasi dari hasil wawancara yang tersusun dan memberi kemungkinan adanya penarikan kesimpulan dan pengambilan tindakan seperti menyajikan data secara naratif. Langkah terakhir adalah melakukan verifikasi atau menarik kesimpulan. 


\section{HASIL PENELITIAN DAN PEMBAHASAN}

\section{Makna Nikah Batin di Kabupaten Padang Pariaman}

Nikah batin adalah pernikahan yang dilakukan oleh seorang mempelai pria dengan seorang mempelai wanita pada malam pertama sebelum melakukan hubungan suami istri, setelah mereka melaksanakan nikah yang sah secara syariat Islam. Nikah batin ini mencontoh kepada nikahnya Nabi Adam, AS dan Siti Hawa di mana Allah sebagai walinya dan malaikat sebagai saksinya dengan mahar dua kalimat syahadat yang bertujuan untuk mendekatkan diri kepada Allah SWT (Buya Jamaris Tk. Sinaro, Ketua MUI Kecamatan Lubuk Alung Kabupaten Padang Pariaman, wawancara, Rabu 6 September 2017)

Menurut pemahaman masyarakat Kabupaten Padang Pariaman yang telah melakukan nikah batin, bahwa nikah secara sah yang telah mereka laksanakan berdasarkan rukun dan syarat sebagaimana yang telah diatur dalam fiqih Islam adalah nikah zahir. Oleh sebab itu pernikahan secara zahir belumlah lengkap jika tidak diteruskan dengan nikah batin, agar diperoleh penyatuan batin antara suami dengan istri dalam rangka membentuk rumah tangga yang sakinah, mawaddah, wa rahmah.

\section{Tata Cara Pelaksanaan Nikah Batin Syarat Nikah Batin}

Adapun yang menjadi syarat untuk dapat melaksanakan Nikah Batin adalah orang yang telah berbai'at kepada guru. Bai'at adalah janji setia kepada guru agar bisa terjalin hubungan antara murid dengan guru. Menurut Buya Jamaris dalam pelaksanaan bai'at para murid akan mempersiapkan tiga buah benda yaitu:

Pertama, cermin cermin adalah pelambangan dari intropeksi diri. Dalam kehidupan, seseorang harus terus bercermin melihat dirinya agar mereka mengetahui salah dan janggal yang ada dalam dirinya. Seperti halnya muka yang bernoda hanya bisa dilihat dengan cermin. Oleh karenanya seorang murid harus terus beristighfar dan berzikir kepada Allah SWT. Kedua, Pisau melambangkan ketajaman ilmu. Untuk bisa kepada maqam fana orang tersebut harus berakal agar ia tidak tersesat dalam maqam fana. Adapun tingkatan maqam adalah: Maqam kasab (syari'at), Maqam billah (hakikat), Maqam Fana (ma'rifat), dan Membawa Kain Putih (Buya Buya Jamaris Tk. Sinaro, wawancara, Rabu 6 September 2017).

Kain putih melambangkan kesucian diri. Kesucian diri antara murid dengan guru. Ketika berbai'at murid akan memegang kain putih tersebut bersama dengan guru. Kemudian guru membaca kalimat yang akan diikuti oleh muridnya: "Radhitubillahi Rabba wabil Islami Diina wabi Muhammadin Nabiyyawwarasula, wali ustazi syaikhan wa dalilan wa murabbiyan, Innallazina yubayi'unaka innama yubayi'unallaha yadullah fauqa aidihim".

\section{Rukun Nikah Batin}

Rukun Nikah batin adalah: 1) Suami, suami adalah pengantin pria yang telah menikah secara sah menurut rukun dan syarat yang telah ditentukan 
dalam figh; 2) Istri, istri adalah pengantin wanita yang telah menikah secara sah menurut rukun dan syarat yang telah ditentukan dalam fiqh; 3) Wali, wali dalam nikah batin adalah Allah SWT sebagaimana nikahnya Nabi Adam AS dengan Siti Hawa menurut kepercayaan masyarkat yang melaksanakan nikah batin di Kabupaten Padang Pariaman; 4) Saksi, saksi nikah batin tidak dipersaksikan oleh manusia akan tetapi masyarakat Kabupaten Padang Pariaman yang melaksanakan Nikah Batin memiliki keyakinan bahwa pernikahannya itu telah disaksikan oleh Malaikat sebagaimana pernikahan Nabi Adam, AS dengan Siti Hawa; 5) Akad, akad yang diucapkan oleh suami kepada istri dalam nikah batin adalah sebagai berikut:

Suami : Assalamu'alaikum ya babul Hawa

Istri : Wa'alaikum salam ya babul Adam

Ijab Suami:Aku nikahi engkau dengan maharnya "asyhadu alla Ilaha illallah wa asyhadu anna Muhammadarrasulullah"

Qabul Istri: Aku terima menikahi engkau dengan "asyhadu anna Muhammadarasullah"

6) Mahar, mahar adalah kalimat syahadat (wawancara dengan beberapa pasangan pelaku nikah batin: Pasangan Raziom dengan Martini, Sintuk, Sabtu 7 Oktober 2017; pasangan Syamsir dengan Hendra Yesi, Lubuk Alung, Minggu 10 September 2017; pasangan Syafrudin dengan Fitri, Lubuk Alung, Sabtu 16 September 2017).

\section{Tata Cara Nikah Batin}

Tata cara nikah batin berbeda dengan nikah menurut fiqih, di mana nikah batin dilakukan setelah pernikahan yang sah menurut aturan fiqih. Adapun ketentuannya adalah sebagai berikut: 1) Dilakukan pada malam pertama sebelum melakukan hubungan suami istri; 2) Hanya dilakukan oleh kedua pasangan dengan wali Allah dan saksi Malaikat; 3) Dengan menjabat tangan istri, kemudian suami mengucapkan "Assalamu'alaikum ya babul Hawa" dan dijawab oleh istri "wa'alaikum salam ya babul Adam" dilanjutkan dengan lafal ijab oleh suami "Aku nikahi engkau dengan maharnya asyhadu alla Ilaha illallah wa asyhadu anna Muhammadarrasulullah, kemudian istri menjawab qabul "Aku terima menikahi engkau dengan "asyhadu anna Muhammadarasullah". 4) Dilakukan dengan penuh kekhusyukan hingga sampai pada kurah (menghantarkan jiwa kepada Allah SWT) dengan durasi waktu 3-5 menit (Buya Jamaris Tk. Sinaro murid Tk. Kuning Zubir, Wawancara, Lubuk Alung, Rabu 6 September 2017)

\section{Urgensi Nikah Batin bagi Masyarakat}

Untuk melihat bagaimana urgennya nikah batin bagi masyarakat Kabupaten Padang Pariaman dapat diperoleh informasi dari beberapa kelompok masyarakat. Pertama, pasangan yang telah melaksanakan nikah batin. Kedua, para niniak mamak yang memberikan pituah adat dan nikah batin bagi kemenakannya yang akan melangsungkan akad nikah. Ketiga, para Tuangku (ulama) tarekat Syatariyah 
selaku pemimpin jama'ahnya.

\section{Pasangan yang telah Melaksanakan Nikah Batin}

Untuk mendapatkan informasi ini peneliti telah mewawancari 15 (lima belas) pasang suami istri yang telah melaksanakan nikah batin di daerah Kabupaten Padang Pariaman. Menurut pasangan Muzahiril Azmi dengan Murni, nikah batin merupakan bukti kepatuhan dan kekonsistenan antara murid dan guru. Nikah batin adalah pertanda keizinan dan pemberian restu oleh guru kepada muridnya untuk melangsungkan pernikahan yang disyariatkan agama.

Di samping itu, menurut mereka, nikah batin bertujuan untuk menyatukan batin mereka. Secara kongkritnya, penyatuan batin itu dalam rangka mencapai kelanggengan hubungan pernikahan yang telah mereka lakukan di KUA dan mendapatkan kehidupan rumah tangga yang harmonis. Menurut mereka, ada perbedaan yang dirasakan setelah batin disatukan oleh guru. Kedekatan batin antara mereka jauh lebih baik dari pada sebelum disatukan oleh guru.Tegas mereka, hal ini diperkuat dengan kenyataan yang mereka dapati pada pasangan yang tidak melakukan nikah batin, sering terjadi pertengkaran bahkan berujung kepada perceraian.

Pasangan Syamsudin dan Fitri memahami bahwa nikah batin adalah ajaran agama yang wajib ditaati dan jika tidak melaksanakan nikah batin berarti tidak menjalankan ajaran agama, bahkan dapat berakibat kepada kehidupan rumah tangga, yaitu keluarga yang berantakan. Menurut mereka nikah batin adalah alat yang dapat menyatukan hati dan memperkuat jalinan kasih antara seorang pria dan wanita yang telah melakukan pernikahan secara syara'.

Pasangan Syamsir dan Hendra Yesi menilai bahwa nikah batin bukan sekedar bertujuan mempertahankan keutuhan kehidupan berumah tangga. Nikah batin, menurut mereka, mengandung nilai-nilai sufi. Kalau pernikahan di KUA merupakan pernikahan secara syara' maka nikah batin adalah melengkapi pernikahan yang telah dilakukan secara syara', karena dalam pengamalan ajaran agama itu mencakup persoalan syara' dan hakekat. Di samping itu, nikah batin juga mengandung makna hubungan pasangan suami isteri dengan Allah sebagai Tuhan alam semesta dalam ilmu tarekat. Selanjutnya, Syamsir menambahkan bahwa nikah batin itu juga berisikan tuntunan tentang cara hubungan intim bagi pasangan suami isteri yang telah melaksanakan pernikahan secara syara'. Melalui nikah batin, pasangan suami isteri diajarkan cara berhubungan intim agar tidak memperturutkan nafsu hewani dalam berjima' dan menjauhkan diri dari syetan, dengan tujuan untuk memperoleh keturunan yang shaleh.

Untuk tanggapan pasangan suami isteri yang lain tentang nikah batin di Kabupaten Padang Pariaman tidak peneliti deskripsikan lebih lanjut, karena penyataan mereka tentang nikah batin mempunyai pandangan dan pemahaman yang sama dengan persepsi pasangan suami isteri yang telah dikemukakan di atas.

Berdasarkan informasi yang diperoleh bahwa keberadaan nikah batin 
bagi masyarakat Kabupaten Padang Pariaman maka dapat disimpulkan bahwa urgensi nikah batin adalah: Pertama, Merupakan wadah untuk mendapatkan keharmonisan kehidupan dalam berumahtangga, karena melalui nikah batin terjadi penyatuan pandangan antara suami dan isteri tentang kehidupan berumahtangga. Jika hal ini sudah diperoleh maka kelanggengan rumah tangga akan mereka dapati dan terhindar dari perceraian, karena dalam pemahaman mereka banyaknya angka perceraian di pengadilan agama terjadi disebabkan pasangan tersebut tidak melaksanakan nikah batin; Kedua, Nikah batin adalah penyempurna dalam menjalankan ajaran agama, karena ajaran agama itu mempunyai pengamalan secara syara' dan hakikat. Pernikahan di KUA adalah menjalankan syara' dan nikah batin merupakan pengamalan secara hakikat. Dengan nikah batin pasangan suami isteri itu telah menyempurnakan pengamalan ajaran agamanya dan begitu juga sebaliknya bagi orang tidak melaksanakan nikah batin. Karena itu, nikah batin dalam persepsi mereka merupakan suatu keharusan untuk melengkapi ajaran agama.

\section{Ninik Mamak selaku Pemimpin Adat}

Dalam pandangan Niniak Mamak selaku pemimpin adat, nikah batin merupakan tradisi yang sudah berlangsung sejak dahulunya. Nikah batin adalah perbauran ajaran agama dengan ketentuan adat."adat basandi syara' syara' basandi kitabullah". Karena itu, nikah batin adalah ketentuan syara' yang sudah menjadi tradisi atau adat. Lebih lanjut dikemukakannya melaksanakan nikah batin berarti melaksanakan adat.

Menurut Apriyaldi Datuak Talanai, nikah batin bukan hanya sebatas masalah agama tapi juga masalah adat. Nikah batin, dalam penjelasannya, bagian dari pelaksanaan adat. Hal ini dapat dibuktikan pada waktu acara "maanta marapulai" oleh pihak keluarga lakilaki. Sewaktu "marapulai dikatangahan" dan hendak memasuki kamar "anak daro" maka dilaksanakanlah nikah batin, yaitu dengan mengucapkan akad nikah batin. Apriyaldi Datuak Talanai menambahkan bahwa pelaksanaan nikah batin seperti inilah yang diajarkan mamak kepada kemenakannya yang hendak melangsungkan pernikahan.

Penuturan Apriyaldi Datuak Talanai di atas memberikan pemahaman bahwa nikah batin akan terlaksana dengan sendirinya jika terjadi acara "maanta marapulai", karena nikah batin merupakan bagian terakhir dari acara "maanta marapulai" tersebut. Tradisi "maanta marapulai" itu adalah tradisi yang selalu diturunkan oleh mamak kepada kemenakannya yang akan melangsungkan pernikahan melalui pituah mamak kepada kemenakan sebelum pernikahan tersebut, mulai dari adab memasuki rumah mertua pertama kali dan untuk menjalani kehidupan baru di sana (Apriyaldi Datuak Talanai, Wawancara, Sintuk, Minggu 15 Oktober 2017).

Berbeda dengan pendapat pemuka adat terdahulu, Drs. Asril Datuak Rangkayo Basa, SH selaku ketua Kerapatan Adat Nagari (KAN) Lubuk Alung menjelaskan bahwa pernikahan 
yang dilakukan pasangan suami isteri di KUA sudah mencakup nikah secara lahir dan batin. Menurutnya, nikah secara lahir dinyatakan dengan pengucapan ijab dan qabul sedangkan nikah secara batin melalui niat untuk menikah yang sudah ada dalam hati pasangan tersebut. Nikah itu, dalam pemahamannya, hanya dilakukan satu kali, yaitu yang diselenggarakan di KUA. Jika nikah harus dilakukan dua kali maka dibutuhkan dalil sebagai alasan untuk mengerjakannya (Asril DT. Rangkayo Basa, Wawancara, Lubuk Alung, Jum'at 22 September 2017).

\section{Tuangku (ulama) Tarekat Syatariyah selaku pemimpin jama'ahnya}

Praktek nikah batin di Kabupaten Padang Pariaman merupakan ajaran yang terdapat pada Tarekat Syatariyah. Dalam pemahaman pengikut Tarekat Syatariyah, nikah batin adalah ajaran yang mesti diperbuat, karena dengan melaksanakan nikah batin maka kesempurnaan mengamalkan nikah tercapai. Kesempurnaan nikah itu harus mencakup syariat dan hakikat.

Menurut Buya Jamaris Tuangku Sinaro sebagai Ketua MUI Kecamatan Lubuk Alung dan Imam Besar Masjid Raya Nurul Illahi Pasar Lubuk Alung, nikah batin menjalin hubungan hamba dengan Allah SWT dan untuk mencapai kesempurnaan dalam beragama karena agama itu mencakup syariat dan hakikat. Buya Jamaris Tuangku Sinaro memahami bahwa nikah batin ini tidak sekedar mengandung ajaran fiqh semata tetapi juga ada unsur sufismenya. Nikah batin di samping sebagai ajaran agama tetapi juga bertujuan untuk mendekatkan hamba dengan sang Pencipta. Nilai sufisme sangat tinggi pada nikah batin ini sehingga seseorang yang melaksanakan nikah batin mempunyai pemahaman yang mendalam tentang sebuah pernikahan dibanding dengan seseorang yang tidak melaksanakan nikah batin.

Selain bertujuan mendekatkan diri kepada Allah, nikah batin dalam pandangan Buya Jamaris Tuangku Sinaro juga berfungsi sebagai pencapaian hakikat sebuah perbuatan dalam ajaran Tarekat Syatariyah, karena ajaran Tarekat Syatariyah menjelaskan bahwa agama itu mencakup syariat dan hakikat. Jika seseorang telah melaksanakan nikah batin maka ia telah mencapai hakikat pernikahan (Wawancara: Buya Jamaris Tk. Sinaro murid Tk. Kuning Zubir, Lubuk Alung, Rabu 6 September 2017).

Senada dengan ungkapan di atas, Dr. Zainal Tuangku Mudo, M.Ag selaku pimpinan Pondok Pesantren Bustanul Yaqin memberi penegasan bahwa nikah batin itu pada intinya mengacu kepada pencapaian hakikat bagi seseorang. Ia menegemukakan alasan bahwa nikah batin itu pelengkap nikah secara syara' yang telah dilakukan di KUA (Zainal Tk. Mudo, Wawancara, Lubuk Alung, Jum'at 15 September 2017).

Di samping ketiga tuangku terdahulu, Nofriandi, MA Tuangku Imam selaku guru Ponpes Nurul Yaqin menegaskan bahwa pelaksanakan nikah batin di Kabupaten Padang Pariaman merupakan pengamalan ajaran Tarikat Syatariyah. Bagi pengikut ajaran Tarikat Syatariyah, nikah batin adalah ajaran yang harus dilaksanakan karena nikah 
batin jalan untuk mencapai kesempurnaan amalan seseorang dalam masalah nikah, sebagaimana diutarakan tokoh Tarekat Syatariyah terdahulu.

Berdasarkan beberapa penjelasan dari para informan dan tokoh Tarekat Syatariyah di atas dapat disimpulkan bahwa pelaksanakan nikah batin di Kabupaten Padang Pariaman merupakan pengamalan ajaran Tarikat Syatariyah. Pelaksanaan nikah batin tersebut dalam rangka mendekatkan diri kepada Allah sebagai Sang Pencipta dan mencapai kesempurnaan amalan seorang hamba, yakni secara syariat dan hakikat. Nikah batin merupakan amalan secara hakikat dalam masalah nikah.

\section{Respon Lembaga Keagamaan Islam terhadap Praktek Nikah Batin}

Respon lembaga keagamaan yang dimaksud di sini adalah tanggapan tentang nikah batin yang diberikan oleh kepala Kantor Urusan Agama (KUA) Kecamatan Lubuk Alung, Kecamatan Sintuk Toboh Gadang dan Kecamatan Enam Lingkung. Menurut Kepala Kantor Urusan Agama (KUA) Kecamatan Lubuk Alung bahwa tidak ada pemisahan antara nikah lahir dan nikah batin,karena pada saat melakukan akad nikah yang diselenggarakan oleh pihak KUA sudah terjalin hubungan antara suami istribaik secara lahir maupun batin. Menurutnya, pemahaman seperti ini didasarkan kepada pengertian pernikahan yang terdapat dal am Undang Undang No. 1 Tahun 1974 tentang perkawinan menegaskan bahwa perkawinan adalah ikatan lahir batin antara seorang pria dengan seorang wanita sebagai suami istri dengan tujuan membentuk keluarga (rumah tangga) yang bahagia dan kekal berdasarkan Ketuhanan Yang Maha Esa.

Lebih lanjut dikemukakan oleh Syafral Abdi, Kepala KUA Kecamatan Lubuk Alung (2017) bahwa pasangan suami isteri yang telah melangsungkan pernikahan di Kantor Urusan Agama (KUA) tidak perlu lagi melaksanakan nikah batin,karena tidak terdapat istilah nikah batin dalam kajian fiqh (hukum Islam).

Senada dengan Kepala KUA Kecamatan Lubuk Alung, Kepala KUA Kecamatan Sintuk Toboh Gadang menjelaskan bahwa pelaksanaan pernikahan di KUA mengacu kepada Undang Undang No. 1 Tahun 1974 tentang Perkawinan dan Kompilasi Hukum Islam. KUA tidak mengenal istilah nikah batin bahkan Kepala KUA Sintuk Toboh Gadang menyatakan bahwa dengan hanya melakukan nikah batin seorang pria dan wanita itu belum terikat dalam pernikahan. Nikah batin yang dipraktikan diakui masyarakat sebagai bentuk nikahnya nabi Adam dan Siti Hawa. Dalam hal ini, secara tegas Kepala KUA Kecamatan Sintuk Toboh Gadang membantah bahwa kita berada pada syariat Nabi Muhammad dan bukan pada syariat Nabi Adam. Syariat Nabi Adam telah terhapus dengan datangnya syariat Nabi Muhammad (Syafri Yendi, Kepala KUA Kecamatan Sintuk Toboh Gadang, Wawancara, Kantor KUA Kecamatan Sintuk Toboh Gadang, Senin 9 Oktober 2017).

Tidak berbeda dengan dua Kepala KUA sebelumnya, Kepala KUA Kecamatan Enam Linkung menjelaskan bahwa nikah yang sah adalah nikah yang telah dilakukan sesuai dengan peratuan perundang-undangan yang 
berlaku di Indonesia dan hal itu sudah mengikat seorang pria dengan seorang wanita secara lahir dan batin. Di KUA hanya menyelenggarakan pernikahan menurut peraturan pemerintah. Ketika pernikahan sudah dilaksanakan sesuai aturan yang berlaku maka perkara nikah batin itu termasuk urusan murid dengan gurunya pada pondok-pondok pesantren salafiyyah di Padang Pariaman atau antara kemenakan dengan mamaknya yang akan menyampaikan persoalan adaik mauduik sebelum pernikahan dilakukan (Kasmir, Kepala KUA Kecamatan Enam Lingkung, Wawancara, Kantor KUA Kecamatan Enam Lingkung, Senin 2 Oktober 2017).

\section{PENUTUP}

Nikah batin adalah nikah yang dilakukan oleh seorang pria dengan seorang wanita pada malam pertama sebelum melakukan hubungan suami istri, setelah mereka melaksanakan nikah secara syariat Islam. Nikah batin ini mencontoh kepada nikahnya Nabi Adam dan Siti Hawadi mana Allah sebagai walinya dan malaikat sebagai saksinya dengan mahar dua kalimat syahadat yang bertujuan untuk mendekatkan diri kepada Allah SWT

Informasi dari Pelaku nikah batin, ninik mamak dan tokoh Tarekat Syatariyah dapat disimpulkan bahwa pelaksanakan nikah batin di Kabupaten Padang Pariaman merupakan pengamalan ajaran Tarikat Syatariyah. Pelaksanaan nikah batin tersebut dalam rangka mendekatkan diri kepada Allah SWT dan mencapai kesempurnaan amalan seorang hamba, yakni secara syariat dan hakikat. Nikah batin merupakan amalan secara hakikat dalam masalah nikah.

Komentar Lembaga Keagamaan yang dalam hal ini adalah Kantor Urusan Agama (KUA). Tidak ada pemisahan antara nikah lahir dan nikah batin, karena pada saat melakukan akad nikah yang diselenggarakan oleh pihak KUA sudah terjalin hubungan antara suami istri baik secara lahir maupun batin. Pemahaman seperti ini didasarkan kepada pengertian pernikahan yang terdapat dal am Undang Undang No. 1 Tahun 1974 tentang perkawinan menegaskan bahwa perkawinan adalah ikatan lahir batin antara seorang pria dengan seorang wanita sebagai suami istri dengan tujuan membentuk keluarga (rumah tangga) yang bahagia dan kekal berdasarkan Ketuhanan Yang Maha Esa. Karena itu, pasangan suami isteri yang telah melangsungkan pernikahan di Kantor Urusan Agama (KUA) tidak perlu lagi melaksanakan nikah batin, karena tidak terdapat istilah nikah batin dalam kajian fiqh (hukum Islam).

\section{DAFTAR PUSTAKA}

Amran, Rusli. (1980). Sumatera Barat Hingga Plakat Panjang. Jakarta: Sinar Harapan.

Asnan, Gusti, dkk. (2007). Memikir Ulang Regionalisme Sumatera Barat Tahun 1950-an. Jakarta: Yayasan Obor Indonesia. (2013). Adabiah: Perintis

Pendidikan Moderen Di Sumatera Barat. Yogyakarta: Penerbit Ombak.

Azra, Azyumardi. (2000). Islam Substantif Agar Islam Tidak Jadi Buih. Bandung: Rosda Karya. 
Badan Pusat Statistik. (2003). Bukittinggi dalam Angka 2000. Bukittinggi: Badan Pusat Statistik.

Baikoeni, Efri Yoni. (2014). Patriot Negara Kepulauan, Jakarta: Pandu Aksara Publishing.

Berkhofer, Robert F. (1971). A Behavioral Approach to Historical Analysis. New York: fte Free Press.

Boland, B.J. (1985). Pergumulan Islam di Indonesia 1945-1970. Jakarta: Grafiti Press.

Chaniago, Danil Mahmud, dkk. (2014). Biografi Rektor IAIN Imam Bonjol Padang 1966- 2015. Padang: Imam Bonjol Press.

Chaniago, Hasril. (2010). 101 Orang Minang Di Pentas Sejarah. Padang: Yayasan Citra Budaya Indonesia.

Departemen Pendidikan dan Kebudayaan RI. (2001). Kamus Besar Bahasa Indonesia. Jakarta: Balai pustaka.

Dobbin, Christine. (2008). Islamic Revivalism in a Changing Peasant Economy, (Gejolak Ekonomi, Kebangkitan Islam dan Gerakan Paderi). Depok: Komunitas Bambu.

Drakard, Jane. (1999). A Kingdom of Words: Language and Power In Sumatra (South-East Asian Historical Monographs). USA: Oxford University Press.

Esmara, Hendra. (1996). Untuk Kejayaan Bangsa. Jakarta: PT. Gramedia Widiasarrana Indonesia.

Hadler, Jeffry. (2010). Sengketa Tiada Putus: Matriarkat, Reformisme Islam, dan Kolonialisme di Minangkabau. Jakarta: Freedom Institute.

Hamka. (1996). Dari Perbendaharaan Lama. Jakarta: Pustaka Panjimas.
Kahin, Audrey. (2008). Dari Pemberontakan Ke Integrasi: Sumatera Barat dan Politik Indonesia 1926-1998. Jakarta: Yayasan Obor Indonesia.

Karsya, Lindo. (2005). Dari Gubernur M. Nasroen Sampai Zainal Bakar 1947-2005. Padang: PT. Genta Singgalang Press.

Kayo, Khatib Pahlawan \& Marjohan. (2010). Muhammadiyah Minangkabau (Sumatera Barat) dalam Perspektif Sejarah. Yogyakarta: Surya Sarana Grafika.

Leirissa, R.Z. (1991). PRRI/Permesta: Strategi Membangun Indonesia Tanpa Komunis. Jakarta: Grafit Press.

Manan, Imran. (1989). Dasar-dasar Sosial Budaya Pendidikan. Jakarta: Departemen Pendidikan dan Kebudayaan RI.

Murodi.(1999).MelacakAsal-usulGerakan Paderi di Sumatera Barat. Jakarta: Logos Wacana Ilmu.

Musri, Muhapril. (2015). Zainuddin Labay elYunusy, Akar-akar Pembaharuan Pendidikan Islam Di Minangkabau Awal Abad XX. Padang: Imam BonjolPress.

Na'im, Muchtar. (1984). Merantau Pola Migrasi Suku Minangkabau. Jakarta: Rajawali Press.

Nain, Sjafnir Aboe. (2008). 200 th Tuanku Imam Bonjol: Sejarah Intelektual Islam di Minangkabau 17841832. Padang: Suara Muhammadiyah.

Nata, Abuddin. (2001). Sejarah Pertumbuhan dan Perkembangan Lembaga-lembaga Pendidikan IslamdiIndonesia. Jakarta:PT Grasindo.

- (2002). Dari Ciputat, Cairo,

Hingga Colombia. Jakarta:IAIN Jakarta Press.

------. (2010). Manajemen Pendidikan.

Jakarta: Kencana Prenada Media Group. 
Noer, Deliar. (1988). Gerakan Moderen Islam di Indonesia. Jakarta: LP3ES.

Panitia Penyusun buku 10 tahun IAIN Imam Bonjol. (1976). Buku Peringatan Dies Natalis Ke-10 IAIN Imam Bonjol. Padang: Sumatera Offset.

Peacock, James L. (1983). Pembaharu dan Pembaharuan Agama. (terjemah oleh Muhadjir Darwin). Yogyakarta: PT. Hanindita.

Pusat Bahasa Departemen Pendidikan Nasional RI. (2001). Kamus Besar Bahasa Indonesia. Edisi Ketiga. Jakarta: Balai Pustaka.

Rajab, Muhammad. (1970). Perang Paderi di Sumatera Barat 1803-1838. Jakarta: Perpustakaan Perguruan Kementerian Pendidikan dan Kebudayaan.

Ramayulis. (2011). Ilmu Pendidikan Islam.

Jakarta: Kalam Mulia.

Ramli, Rusydi. (2008). Memory Kilas Balik Pusat Pengabdian Kepada Masyarakat IAIN Imam Bonjol Padang. Padang: Pusat Pengabdian Kepada Masyarakat IAIN Imam Bonjol Padang.

Safwan, Mardanas \& Kutoyo, Sutrisno. (1980). Sejarah Pendidikan Daerah Sumatera Barat. Jakarta: Departemen Pendidikan dan Kebudayaan: Proyek Inventarisasi dan DokumentasiKebudayaan Daerah.
Shiddiqi, Nourouzzaman. (1984). Menguak Sejarah Muslim. Yogyakarta: PLP2M.

Steenbrink, Karel A. (1988). Beberapa Aspek Tentang Islam di Indonesia Pada Abad Ke 19. Jakarta: PT. Bulan Bintang.

Sumarjan, Selo. (1991). Perubahan Sosial di Yogyakarta. Yogyakarta: Gajah Mada University Press.

Tim Penyusun. (2015). EMIS IAIN Imam Bonjol Padang Tahun2015, Padang:IAIN IBPress.

Yunus, A. Riva'i. dkk. (1976). Buku Pringatan Dies Natalis ke 10 IAIN Imam Bonjol 1966-1976. Padang: Ikhlas.

Yunus, Mahmud. (1979). Sejarah Pendidikan Islam di Indonesia. Jakarta: Mutiara.

Yunus, Yulizal. dkk. (1996). IAIN Imam Bonjol 50 Tahun. Padang: IAIN IB Press.

Zed, Mestika. dkk. (2001). Riwayat Hidup Ulama Sumatera Barat dan Perjuangannya. Padang: Angkasa Raya. (1998). Sumatera Barat di Panggung Sejarah 1945-1995. Jakarta: Pustaka Sinar Harapan. 
